УДК 691-4

\title{
АНАЛИЗ ГРАНУЛОМЕТРИЧЕСКОГО СОСТАВА ЗОЛОШЛАКОВЫХ ОТХОДОВ ТЭЦ КЕМЕРОВСКОЙ ОБЛАСТИ.
}

\author{
Даянова София Александровна \\ Студент \\ ФГБОУ «Кузбасский Государственный технический университет им. Т.Ф. Горбачева», Гилязидинова \\ Наталья Владимировна \\ к.т.н., доцент кафедры \\ Строительного производства и экспертизы недвижимости», \\ Россия, Кемеровская область, г. Кемерово.
}

\begin{abstract}
Аннотация. Цель: исследовать золошлаковые отходы ТЭЦ Кемеровской области на возможность их использования в качестве заполнителя для бетонов.

Задачи: изучить гранулометрический состав золошлаковых отходов; определить, соответствует ли зерновой состав требованиям ГОСТ; определить вид заполнителя, мелкий или крупный.

Возможности практического применения: данное исследование направлено на увеличение вторичного использования золошлаковых отходов, снижения количества и объемов отвалов ЗШО и уменьшения их вредного влияния на окружающую среду.

Abstract. Aim: to research ash and slag waste from thermal power plants on the possibility of using them as a concretes' aggregate.

Tasks: to explore ash and slag waste's granulometric composition; to determine if the granulometric composition meets the state standard's requirements; to explore the kind of the aggregate, fine or coarse.

Possibility of practical using: this researching is directed to increasing of ash and slag waste reuse, decline quantity and volume of ash and slag waste and reduction their poison impact on the environment.

Ключевые слова (Keywords): Золошлаковые отходы (ash and slag waste), гранулометрический состав (granulometric composition), твердые частицы (solid particles), пылевидные частицы (dust particles), зерна (granule), фракция (fraction).
\end{abstract}

Несмотря на то, что огромное количество научных исследований направлено на поиск и применение альтернативных источников энергии, в России по-прежнему используются электростанции, работающие за счёт сжигания топлива. Такой способ получения энергии на сегодняшний день является одним из наиболее выгодных, однако он не решает проблему загрязнения окружающей среды. В результате сжигания каменного угля российские электростанции образуют около 22 млн. тонн золошлаковых отходов. И только $4 \%$ используется вторично по сравнению с тем показателем в Европе в 30-50 \%. Поэтому целью настоящего исследования является изучение золошлаковых отходов (ЗШО), производимых ТЭЦ Кемеровской области на возможность их использования в качестве заполнителя для бетона.

Руководствуясь целью, поставлены две основные задачи: определить гранулометрический состав отходов; сделать заключение, соответствует ли зерновой состав ЗШО требованиям нормативной документации. В ходе исследования были применены следующие методы исследования: измерительный и сравнительный.

Гранулометрический состав - одна из основных характеристик заполнителя. Именно по процентным соотношениям полных остатков зерен каждой фракции делается заключение о принадлежности золошлака к крупному или мелкому заполнителю.

Для определения зернового состава из отвала электростанции в местах, определенных в соответствии с [1] были отобраны 11 проб. Перед проведением испытаний все образцы были подвергнуты визуальному осмотру.

Образец №1: густая глиновидная масса высокой влажности, пластичная, хорошо держит форму.

Данный образец получен с помощью гидроудаления - один из способов удаления золошлаковых отходов из печей электростанций. Пылевидная фракция, преобладающая в образце, проявила пуццолановые свойства. 


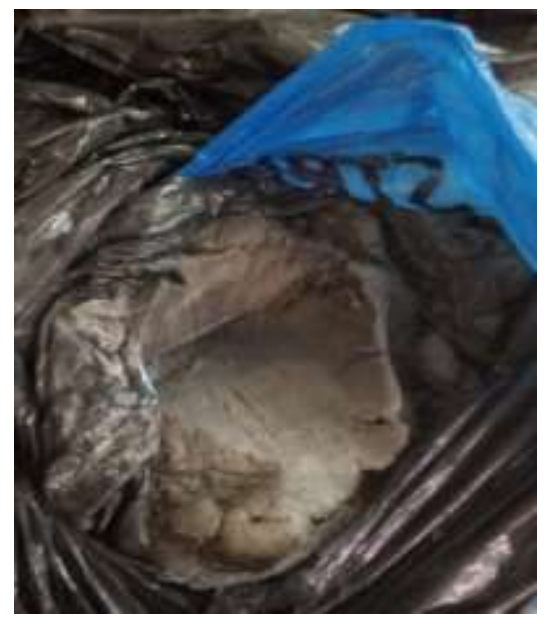

Рис.1: Внешний вид образиа №1.

Образцы № 2, №3, №4, №5: золошлаковые смеси с крупными твердыми зернами и небольшим содержанием стекловидных пластин; отдельные зерна превышают в диаметре 20 мм.

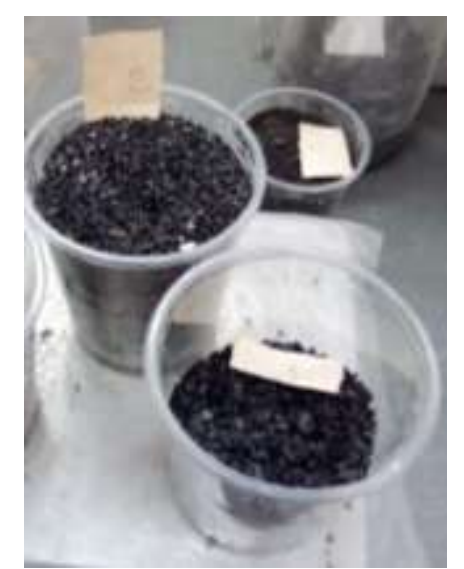

Рис. 2: Внешний вид образиов 2 и 4 .

Образцы №6, №8, №9, №10, №11: золошлаковые смеси без крупных твердых частиц; в пробах преобладают пылевидные фракции.

Образец №7: золошлаковая смесь с содержанием как крупных твердых, так и мелких пылевидных частиц. Последние в результате гранулирования образовали более крупные частицы, хрупкие на ощупь.

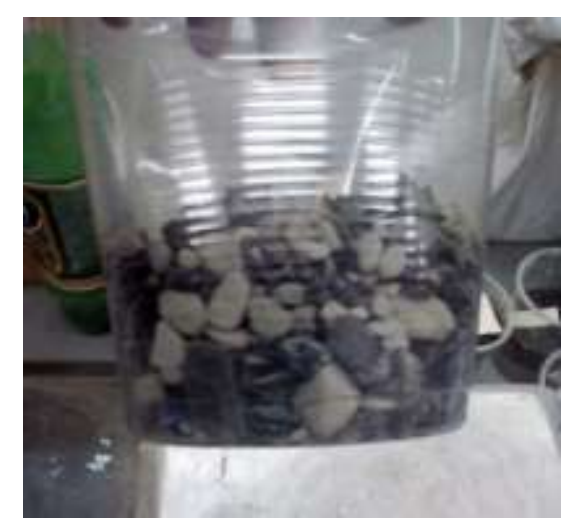

Рис. 3: Внешний вид образиа №3.

В соответствии с [2] все пробы были высушены в сушильном шкафу до постоянной массы. 


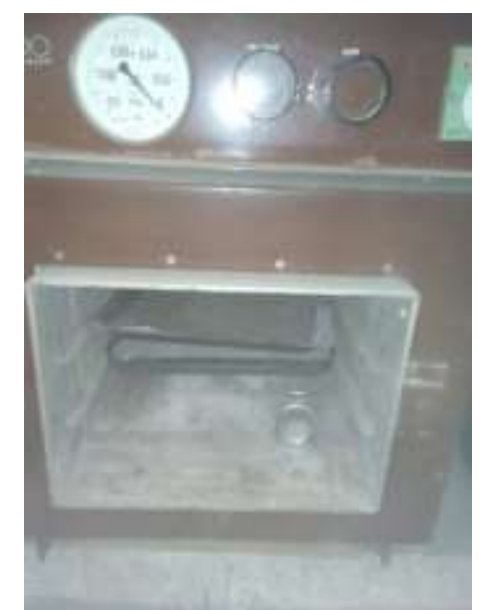

Рис. 4: Сушка образиов в сушильном шкафу.

Образец №1 после высушивания превратился в твердую хрупкую массу, рассыпающуюся при малейшем механическом воздействии.

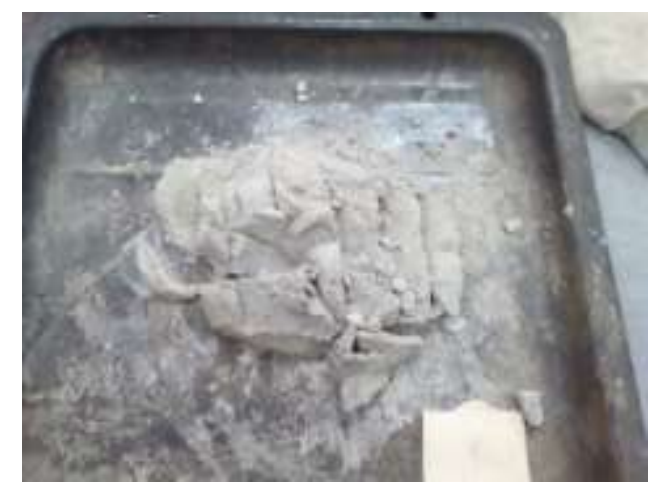

Рис.5: Внешний вид образца №1 после высушивания.

Поскольку пробу №1 невозможно разделить на фракции, она исключается из испытания.

Все остальные образцы были рассеяны с помощью набора стандартных сит для фракционирования песка (сита выбраны согласно требованиям [1]).

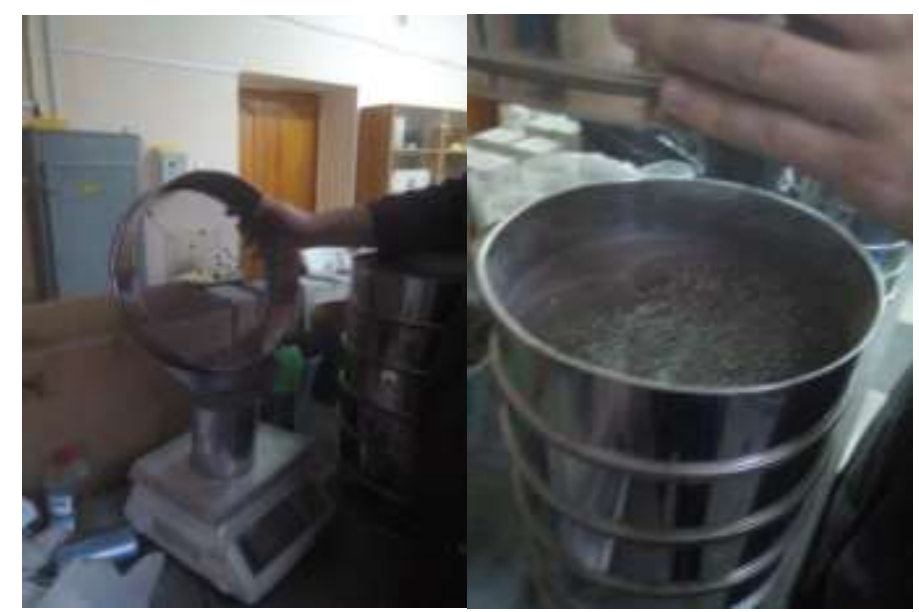

Рис. 6: Измерение гранулометрического состава золошлаковых отходов.

Результаты вычислений приведены в таблице 1, где а - частные остатки на ситах, \%; А - полные остатки на ситах, \%. Таблица 1. 


\begin{tabular}{|c|c|c|c|c|c|c|c|c|c|c|c|c|c|c|c|c|c|c|}
\hline \multirow{3}{*}{$\begin{array}{c}\text { Ном } \\
\text { ер } \\
\text { про } \\
\sigma\end{array}$} & \multicolumn{18}{|c|}{ Гранулометрический состав,\% } \\
\hline & \multicolumn{2}{|c|}{10} & \multicolumn{2}{|c|}{7.5} & \multicolumn{2}{|c|}{5} & \multicolumn{2}{|c|}{2.5} & \multicolumn{2}{|c|}{1.25} & \multicolumn{2}{|c|}{0.63} & \multicolumn{2}{|c|}{0.315} & \multicolumn{2}{|c|}{0.16} & \multicolumn{2}{|c|}{$<0.16$} \\
\hline & $\mathrm{a}$ & A & a & A & $\mathrm{a}$ & A & $\mathrm{a}$ & A & a & A & $\mathrm{a}$ & A & $\mathrm{a}$ & A & $\mathrm{a}$ & A & a & A \\
\hline 1 & \multicolumn{18}{|c|}{ Невозможно определить } \\
\hline 2 & $\begin{array}{l}18 . \\
56\end{array}$ & $\begin{array}{l}18 . \\
56\end{array}$ & $\begin{array}{l}18 . \\
56\end{array}$ & $\begin{array}{l}37 . \\
11\end{array}$ & $\begin{array}{c}9.2 \\
8\end{array}$ & $\begin{array}{l}46 . \\
39\end{array}$ & $\begin{array}{l}13 . \\
40\end{array}$ & $\begin{array}{l}59 . \\
79\end{array}$ & $\begin{array}{l}17 . \\
53\end{array}$ & $\begin{array}{l}77 . \\
32\end{array}$ & $\begin{array}{l}9 . \\
28\end{array}$ & $\begin{array}{c}86 . \\
60\end{array}$ & $\begin{array}{c}6.1 \\
9\end{array}$ & $\begin{array}{l}92 . \\
78\end{array}$ & $\begin{array}{c}4.1 \\
2\end{array}$ & $\begin{array}{l}96 . \\
91\end{array}$ & $\begin{array}{c}3.0 \\
9\end{array}$ & $\begin{array}{c}100 . \\
00\end{array}$ \\
\hline 3 & $\begin{array}{l}13 . \\
40\end{array}$ & $\begin{array}{l}13 . \\
40\end{array}$ & $\begin{array}{c}5.1 \\
5\end{array}$ & $\begin{array}{l}18 . \\
56\end{array}$ & $\begin{array}{c}9.2 \\
8\end{array}$ & $\begin{array}{l}27 . \\
84\end{array}$ & $\begin{array}{l}14 . \\
43\end{array}$ & $\begin{array}{l}42 . \\
27\end{array}$ & $\begin{array}{l}24 . \\
74\end{array}$ & $\begin{array}{l}67 . \\
01\end{array}$ & $\begin{array}{l}9 . \\
28\end{array}$ & $\begin{array}{l}76 . \\
29\end{array}$ & $\begin{array}{c}2.0 \\
6\end{array}$ & $\begin{array}{l}78 . \\
35\end{array}$ & $\begin{array}{c}3.0 \\
9\end{array}$ & $\begin{array}{l}81 . \\
44\end{array}$ & $\begin{array}{l}16 . \\
49\end{array}$ & $\begin{array}{c}97.9 \\
4\end{array}$ \\
\hline 4 & $\begin{array}{l}26 . \\
26\end{array}$ & $\begin{array}{l}26 . \\
26\end{array}$ & $\begin{array}{c}9.0 \\
9\end{array}$ & $\begin{array}{l}35 . \\
35\end{array}$ & $\begin{array}{l}11 . \\
11\end{array}$ & $\begin{array}{l}46 . \\
46\end{array}$ & $\begin{array}{l}14 . \\
14\end{array}$ & $\begin{array}{l}60 . \\
61\end{array}$ & $\begin{array}{l}16 . \\
16\end{array}$ & $\begin{array}{l}76 . \\
77\end{array}$ & $\begin{array}{l}9 . \\
09\end{array}$ & $\begin{array}{l}85 . \\
86\end{array}$ & $\begin{array}{c}4.0 \\
4\end{array}$ & $\begin{array}{l}89 . \\
90\end{array}$ & $\begin{array}{c}3.0 \\
3\end{array}$ & $\begin{array}{l}92 . \\
93\end{array}$ & $\begin{array}{c}7.0 \\
7\end{array}$ & $\begin{array}{c}100 . \\
00\end{array}$ \\
\hline 5 & $\begin{array}{l}22 . \\
92\end{array}$ & $\begin{array}{l}22 . \\
92\end{array}$ & $\begin{array}{l}10 . \\
42\end{array}$ & $\begin{array}{l}33 . \\
33\end{array}$ & $\begin{array}{l}12 . \\
50\end{array}$ & $\begin{array}{r}45 . \\
83\end{array}$ & $\begin{array}{l}11 . \\
46\end{array}$ & $\begin{array}{l}57 . \\
29\end{array}$ & $\begin{array}{c}14 . \\
58\end{array}$ & $\begin{array}{l}71 . \\
88\end{array}$ & $\begin{array}{l}4 . \\
17\end{array}$ & $\begin{array}{l}76 . \\
04\end{array}$ & $\begin{array}{c}2.0 \\
8\end{array}$ & $\begin{array}{l}78 . \\
13\end{array}$ & $\begin{array}{c}3.1 \\
6\end{array}$ & $\begin{array}{l}81 . \\
28\end{array}$ & $\begin{array}{l}13 . \\
54\end{array}$ & $\begin{array}{c}94.8 \\
2\end{array}$ \\
\hline 6 & $\begin{array}{c}5.1 \\
3\end{array}$ & $\begin{array}{c}5.1 \\
3\end{array}$ & $\begin{array}{c}2.5 \\
6\end{array}$ & $\begin{array}{c}7.6 \\
9\end{array}$ & $\begin{array}{c}5.1 \\
3\end{array}$ & $\begin{array}{l}12 . \\
82\end{array}$ & $\begin{array}{c}6.4 \\
1\end{array}$ & $\begin{array}{l}19 . \\
23\end{array}$ & $\begin{array}{c}8.9 \\
7\end{array}$ & $\begin{array}{l}28 . \\
21\end{array}$ & $\begin{array}{l}8 . \\
97\end{array}$ & $\begin{array}{l}37 . \\
18\end{array}$ & $\begin{array}{l}14 . \\
10\end{array}$ & $\begin{array}{l}51 . \\
28\end{array}$ & $\begin{array}{l}33 . \\
33\end{array}$ & $\begin{array}{l}84 . \\
62\end{array}$ & $\begin{array}{l}17 . \\
95\end{array}$ & $\begin{array}{c}102 . \\
56\end{array}$ \\
\hline 7 & $\begin{array}{l}12 . \\
90\end{array}$ & $\begin{array}{l}12 . \\
90\end{array}$ & $\begin{array}{c}3.2 \\
3\end{array}$ & $\begin{array}{l}16 . \\
13\end{array}$ & $\begin{array}{c}2.1 \\
5\end{array}$ & $\begin{array}{l}18 . \\
28\end{array}$ & $\begin{array}{c}4.3 \\
0\end{array}$ & $\begin{array}{c}22 . \\
58\end{array}$ & $\begin{array}{c}5.3 \\
8\end{array}$ & $\begin{array}{l}27 . \\
96\end{array}$ & $\begin{array}{l}4 . \\
30\end{array}$ & $\begin{array}{l}32 . \\
26\end{array}$ & $\begin{array}{c}2.1 \\
5\end{array}$ & $\begin{array}{l}34 . \\
41\end{array}$ & $\begin{array}{c}7.5 \\
3\end{array}$ & $\begin{array}{l}41 . \\
94\end{array}$ & $\begin{array}{c}55 . \\
91\end{array}$ & $\begin{array}{c}97.8 \\
5\end{array}$ \\
\hline 8 & $\begin{array}{l}18 . \\
52\end{array}$ & $\begin{array}{l}18 . \\
52\end{array}$ & $\begin{array}{c}2.4 \\
7\end{array}$ & $\begin{array}{l}20 . \\
99\end{array}$ & $\begin{array}{c}3.7 \\
0\end{array}$ & $\begin{array}{r}24 . \\
69\end{array}$ & $\begin{array}{c}6.1 \\
7\end{array}$ & $\begin{array}{l}30 . \\
86\end{array}$ & $\begin{array}{c}4.9 \\
4\end{array}$ & $\begin{array}{l}35 . \\
80\end{array}$ & $\begin{array}{l}4 . \\
94\end{array}$ & $\begin{array}{r}40 . \\
74\end{array}$ & $\begin{array}{c}6.1 \\
7\end{array}$ & $\begin{array}{c}46 . \\
91\end{array}$ & $\begin{array}{c}35 . \\
80\end{array}$ & $\begin{array}{l}82 . \\
72\end{array}$ & $\begin{array}{l}23 . \\
46\end{array}$ & $\begin{array}{c}106 . \\
17\end{array}$ \\
\hline 9 & $\begin{array}{l}10 . \\
13\end{array}$ & $\begin{array}{l}10 . \\
13\end{array}$ & $\begin{array}{c}3.8 \\
0\end{array}$ & $\begin{array}{l}13 . \\
92\end{array}$ & $\begin{array}{c}5.0 \\
6\end{array}$ & $\begin{array}{l}18 . \\
99\end{array}$ & $\begin{array}{c}6.3 \\
3\end{array}$ & $\begin{array}{l}25 . \\
32\end{array}$ & $\begin{array}{c}5.0 \\
6\end{array}$ & $\begin{array}{l}30 . \\
38\end{array}$ & $\begin{array}{l}6 . \\
33\end{array}$ & $\begin{array}{c}36 . \\
71\end{array}$ & $\begin{array}{c}3.8 \\
0\end{array}$ & $\begin{array}{l}40 . \\
51\end{array}$ & $\begin{array}{l}11 . \\
39\end{array}$ & $\begin{array}{c}51 . \\
90\end{array}$ & $\begin{array}{c}48 . \\
10\end{array}$ & $\begin{array}{c}100 . \\
00\end{array}$ \\
\hline 10 & $\begin{array}{l}21 . \\
05\end{array}$ & $\begin{array}{l}21 . \\
05\end{array}$ & $\begin{array}{c}9.4 \\
7\end{array}$ & $\begin{array}{l}30 . \\
53\end{array}$ & $\begin{array}{c}9.4 \\
7\end{array}$ & $\begin{array}{l}40 . \\
00\end{array}$ & $\begin{array}{c}9.4 \\
7\end{array}$ & $\begin{array}{l}49 . \\
47\end{array}$ & $\begin{array}{l}15 . \\
79\end{array}$ & $\begin{array}{l}65 . \\
26\end{array}$ & $\begin{array}{l}9 . \\
47\end{array}$ & $\begin{array}{l}74 . \\
74\end{array}$ & $\begin{array}{c}3.1 \\
6\end{array}$ & $\begin{array}{l}77 . \\
89\end{array}$ & $\begin{array}{c}3.1 \\
6\end{array}$ & $\begin{array}{l}81 . \\
05\end{array}$ & $\begin{array}{l}16 . \\
84\end{array}$ & $\begin{array}{c}97.8 \\
9\end{array}$ \\
\hline 11 & $\begin{array}{c}6.4 \\
1\end{array}$ & $\begin{array}{c}6.4 \\
1\end{array}$ & $\begin{array}{c}2.5 \\
6\end{array}$ & $\begin{array}{c}8.9 \\
7\end{array}$ & $\begin{array}{c}3.8 \\
5\end{array}$ & $\begin{array}{l}12 . \\
82\end{array}$ & $\begin{array}{c}7.6 \\
9\end{array}$ & $\begin{array}{l}20 . \\
51\end{array}$ & $\begin{array}{c}7.6 \\
9\end{array}$ & $\begin{array}{l}28 . \\
21\end{array}$ & $\begin{array}{l}3 . \\
85\end{array}$ & $\begin{array}{l}32 . \\
05\end{array}$ & $\begin{array}{c}6.4 \\
1\end{array}$ & $\begin{array}{l}38 . \\
46\end{array}$ & $\begin{array}{l}24 . \\
36\end{array}$ & $\begin{array}{l}62 . \\
82\end{array}$ & $\begin{array}{l}42 . \\
31\end{array}$ & $\begin{array}{c}105 \\
13\end{array}$ \\
\hline
\end{tabular}

Крупность заполнителя определяется исходя из количества зерен фракций больше 5 мм, меньше 0,315 мм и больше 0,315 мм. Анализ гранулометрического состава представлен в таблице 2.

Таблица 2.

\begin{tabular}{|c|c|c|c|c|c|}
\hline \multirow{2}{*}{ № пробы } & \multicolumn{3}{|c|}{ Содержание фракций, $\%$} & \multirow{2}{*}{ Вид заполнителя } & Примечания \\
\cline { 2 - 3 } & $>5$ мм & $>0.315$ мм & $<0.315$ мм & & Много фракции $>5$ мм \\
\hline 2 & 37.11 & 92.79 & 7.21 & Крупный & Много фракции $>5$ мм \\
\hline 3 & 18.55 & 59.79 & 40.21 & & Много фракции $>5$ мм \\
\hline 4 & 35.35 & 84.83 & 16 & Крупный & Много фракции $>5$ мм \\
\hline 5 & 34.3 & 72.84 & 27.16 & Крупный & Много фракции $<0.315$ мм \\
\hline 6 & 7.56 & 45.94 & 54.06 & Мелкий & Много фракции $>5$ мм \\
\hline 7 & 16.13 & 65.55 & 34.41 & Мелкий & Много фракции $>5$ мм \\
\hline 8 & 20.99 & 53.09 & 46.91 & & Много фракции $>5$ мм \\
\hline 9 & 13.92 & 59.49 & 40.51 & & Много фракции $>5$ мм \\
\hline 10 & 30.53 & 70.31 & 29.69 & Крупный & Много фракции $<0.315$ мм \\
\hline 11 & 9.33 & 38.46 & 69.35 & Мелкий & .
\end{tabular}

Критерии анализа:

- Крупный заполнитель - содержание зерен больше 5 мм ->50\%; зерен больше 0,315 мм - >90\%, фракции меньше 0,315 мм отсутствуют;

- Мелкий заполнитель - содержание зерен больше 5 мм - <10\%; зерен больше 0,315 мм - $\geq 50 \%$, фракций меньше 0,315 мм $-\leq 20 \%$ 
Соответствие зернового состава образцов для крупного и мелкого заполнителя.

Диаграмма 1

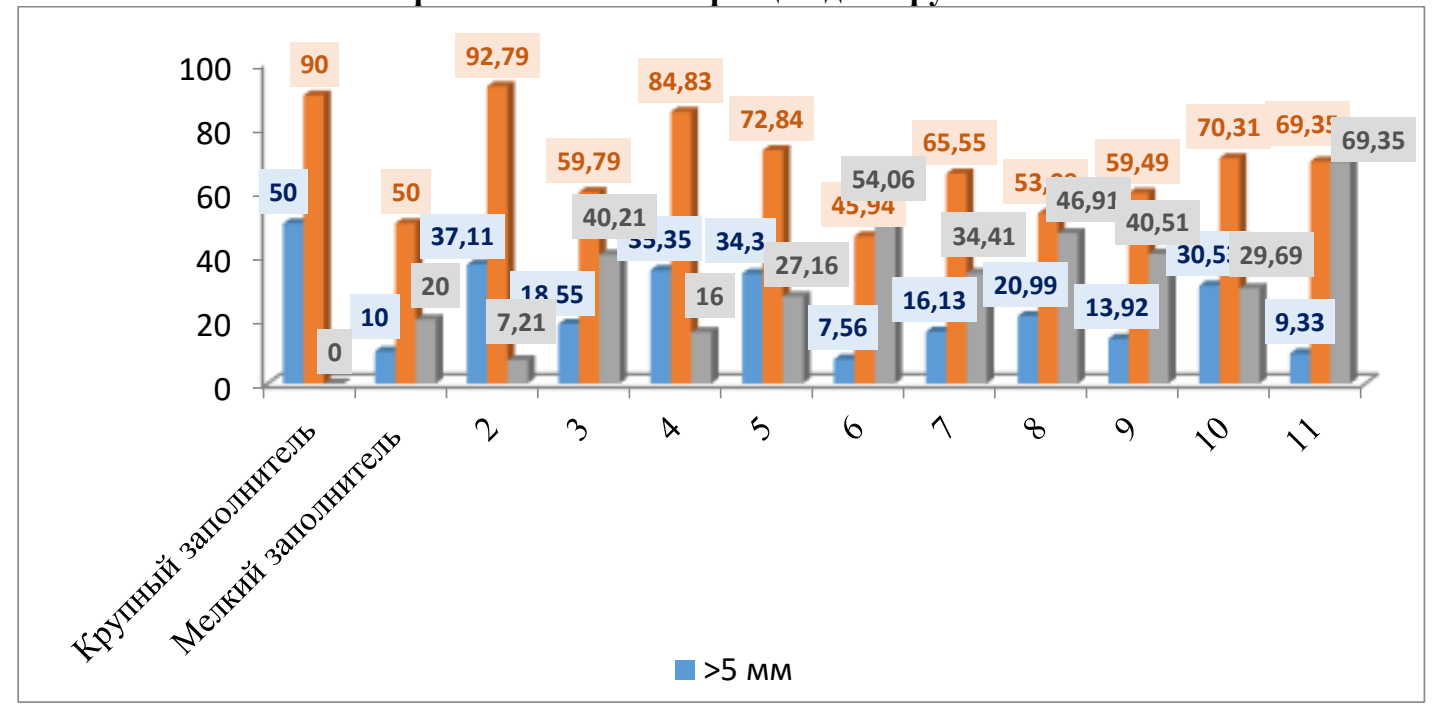

На основании анализа гранулометрического состава можно сделать следующие выводы:

1. Во всех пробах присутствует большое количество мелких пылевидных частиц - так называемой зольной составляющей, которая не допустима для заполнителя бетонной смеси.

2. Гранулометрический состав проб ЗШС не отвечает требованиям ГОСТ 25592-19. Большинство видов проб невозможно точно отнести к тому или иному виду заполнителя. Образец №2 можно условно присвоить к крупным заполнителям, хотя содержание фракций больше 5 мм составляет $37.11 \%$ вместо требуемых $50 \%$, вдобавок, присутствует некоторое количество мелких пылевидных частиц, которых в крупных заполнителях быть не должно. Также условно к крупным заполнителям относятся образцы №4, №5, №10 из-за содержания фракций больше 5 мм на уровне 30-35\%, однако следует отметить недопустимо высокое содержание в пробах фракций меньше 0,315 мм.

Образцы №3,№8,№9 - заполнители средней крупности из-за малого количества зерен больше 5 мм и примерно равного соотношения фракций больше и меньше 0,315 мм. Однако следует заметить, что в пробе №9 крупные и средние зерна не являются обломками твердых пород, они получены в результате грануляции мелких пылевидных частиц. Это условие следует учитывать, поскольку гранулы имеют минимальную прочность и в составе бетонной смеси использоваться не могут.

Образец № 11 можно отнести к мелким заполнителям, но содержание зерен меньше 0,315 мм выше нормы.

Для использования в качестве заполнителя для бетона ЗШС требует оптимизации.

\section{Список литературы.}

ОСТ 25592-19 «Смеси золошлаковые тепловых электростанций для бетонов. Технические условия». ОСТ 8735-88 «Песок для строительных работ. Методы испытаний». 